\title{
El significado de la preposición 'de': un enfoque cognitivo-prototípico
}

\author{
María Soledad Funes* \\ Universidad de Buenos Aires, Argentina
}

\begin{abstract}
Resumen
El carácter léxico de la preposición 'de' no siempre ha sido reconocido debidamente por cuanto las preposiciones no pueden funcionar independientemente y por la variedad de significados que se les atribuye. Considerando este vacío teórico, el presente trabajo, enmarcado en el Enfoque Cognitivo-Prototípico (Lakoff 1987; Langacker 1987, 1991; Hopper 1988; Geeraerts 2007; entre otros), plantea las siguientes hipótesis: a) los distintos valores semánticos de la preposición 'de' (en construcciones adnominales) están organizados sistemáticamente y configuran un ítem polisémico; b) el ítem polisémico 'de' se caracteriza por organizarse (1) mediante una estructura de categoría radial (Lakoff 1987), (2) sobre la base del modelo cognitivo idealizado del punto de referencia (Langacker 1991) y (3) a partir de los atributos de Taylor (1995) para el uso posesivo, que es el uso prototípico; c) finalmente, las construcciones con 'de' que se alejan del valor prototípico siguen guardando relación semántico-pragmática con este por 'semejanza de familia' (Wittgenstein 1988[1953]; Lakoff 1987). Esta relación de semejanza contempla tanto la pérdida como el agregado de atributos
\end{abstract}

*Para correspondencia, dirigirse a: María Soledad Funes (solefunes@gmail.com), Instituto de Lingüística (Facultad de Filosofía y Letras - Universidad de Buenos Aires), 25 de Mayo 217, 1er piso (1002), Buenos Aires. Argentina. 
no presentes en la zona prototípica. Para demostrar estas hipótesis, se analizaron cualitativamente diversos ejemplos de las extensiones semánticas surgidas del sentido central de posesión. Los ejemplos fueron seleccionados de un corpus oral del español de Buenos Aires.

Palabras clave: Enfoque Cognitivo-Prototípico, preposición 'de', ítem polisémico, categoría radial, posesión

\title{
THE MEANING OF THE PREPOSITION 'DE': A COGNITIVE-PROTOTYPE FOCUS
}

\begin{abstract}
The lexical nature of the preposition 'de' has not always been recognized duly. This is because prepositions cannot work independently and also because of the variety of meanings that they convey. In view of this theoretical gap, the present study -in line with the Prototypical-Cognitive Approach (Lakoff 1987, Langacker 1987, 1991, Hopper 1988, Geeraerts 2007, among others)-formulates the following hypotheses: a) the different semantic values of the preposition 'de' (in nominal constructions) are systematically organized and constitute a polysemous item; b) the polysemous item 'de' is characterized by being organized (1) by a radial structure (Lakoff 1987), (2) on the basis of the idealized cognitive model of 'reference point' (Langacker 1991); and (3) through Taylor's (1995) attributes for possessive use, which is its prototypical meaning. Finally, the constructions with 'de' which deviate from the prototypical values maintain a semantico-pragmatic relationship with them by means of the notion of 'family resemblance' (Wittgenstein 1988[1953]; Lakoff 1987). This resemblance relationship includes both the loss and addition of attributes not present within the prototypical area. In order to test hypotheses, different examples of the semantic extensions derived from the central meaning of possession were analysed qualitatively. The data being described was selected from an oral corpus of Buenos Aires Spanish.
\end{abstract}

Key words: Prototypical-Cognitive Approach, preposition 'de', polysemous ítem, radial category, possession

Recibido: 05/04/12 Aceptado: 30/05/12 


\section{INTRODUCCIÓN}

No hay consenso acerca de la especificación semántica de la preposición 'de'. Para algunos autores, no es posible sistematizar sus distintos significados (cfr. Lenz 1935: §333). Otros teóricos resumen todos los usos bajo un solo valor ('origen', en el caso de Alarcos 1994: §287; 'posesión', en el de Fernández Lagunilla y Rebollo 1995: §7.6.3.). Algunas gramáticas se limitan a dar meros inventarios (GRAE 1931: §173; NGLE 2009: §29.71- §29.7ñ) o clasifican 'de' sin agotar los múltiples usos (Gili Gaya 1955: §190). Los autores que analizan más detenidamente los usos de 'de', Trujillo (1971), López (1972), Luque Durán (1980) y Morera (1988), no tienen cuerpos de datos sistematizados ni cuantificados, sino recolección de casos que, finalmente, quedan descontextualizados. Los autores que trabajan con cuantificación, o bien realizan un análisis diacrónico de corpus escrito (Granvik 2003; 2012) o bien subsumen los usos de 'de' a un solo valor, como Rodrigues (2009), quien reduce los múltiples significados de 'de' al de "referente conceptual".

Considerando lo previamente mencionado, el presente trabajo, enmarcado en la Gramática Cognitiva, propone que los distintos valores semánticos de la preposición 'de' en función adnominal ${ }^{1}$ están organizados sistemáticamente y constituyen un ítem polisémico. El uso de 'de' con valor posesivo (en contexto de relación de posesión, como por ejemplo en 1. La casa de mi mamá, $H C C B A$, muestra V) es el uso que muestra la mayor acumulación de atributos en común con el resto de los usos de 'de', por lo que se propone como el uso prototípico. Además, las construcciones con 'de' que se alejan del valor prototípico siguen guardando relación semántico-pragmática con este por 'semejanza de familia' (Wittgenstein 1988[1953]; Lakoff 1987). Esta relación de semejanza contempla tanto la pérdida como el agregado de atributos no presentes en la zona prototípica.

Para demostrar estas hipótesis, se analizaron cualitativamente diversos ejemplos de las extensiones semánticas surgidas del sentido central de posesión. Los ejemplos fueron extraídos de un corpus de registro oral del español de Buenos Aires: el Habla Culta de la Ciudad de Buenos Aires $(H C C B A)$.

Hay dos razones principales para elegir el análisis de la función adnominal antes que la adverbal: en primer lugar, varios autores sostienen la importancia de la función adnominal (Lenz 1935; Rodrigues 2009; entre otros), y en segundo lugar, la mayor frecuencia de usos adnominales por sobre los adverbales. 


\section{ESTADO DE LA CUESTIÓN}

\subsection{LA SEMÁNTICA DE LA PREPOSICIÓN 'DE'}

Respecto del carácter polisémico de la preposición 'de', las Gramáticas hispánicas se pronuncian de manera disímil. Para Lenz (1935: §331), resulta imposible sistematizar los distintos significados. Algunos gramáticos agrupan todos los usos bajo un solo valor: Alarcos (1994: §287) ubica a la preposición 'de' en el grupo de las preposiciones dinámicas (en las que interviene el movimiento, ya sea físico o figurado), denotando 'origen' (Vengo de casa), mientras que Fernández Lagunilla y Rebollo (1995: §7.6.3.) definen 'de' solo con el rasgo [+posesión]. Otras Gramáticas hacen meros inventarios de usos (GRAE 1931: §173; NGLE 2009: §29.71- §29.7ñ) o clasifican 'de' sin agotar los múltiples significados (Gili Gaya 1955: §190).

En cuanto a los trabajos monográficos, son numerosos los autores que han trabajado las preposiciones en estudios especializados. En el presente trabajo nos referiremos únicamente a los que analizaron las preposiciones en la lengua española, dejando para un estudio más amplio la inclusión de los aportes de teóricos no hispánicos, como Brøndal, Tesnière, Pottier, entre otros.

Trujillo (1971) clasifica las preposiciones en dos grupos, de acuerdo con la presencia o ausencia del sema 'movimiento'. 'De' pertenece al grupo [+movimiento], con el significado de 'alejamiento de un límite', e indica más precisamente origen o punto de partida (espacio-temporal-conceptual). Como se observará, esta descripción no puede abarcar todos los usos que esta preposición posee.

M. L. López (1972) parte de la teoría de Pottier $^{2}$ para definir la significación de las preposiciones. Para esta autora, la preposición 'de' representa un movimiento de alejamiento de un límite, y puede expresar

2 Pottier (1962) realizó representaciones unitarias de las preposiciones. Así, agrupó la multiplicidad de sentidos discursivos de las preposiciones en tres campos de aplicación (espacial, temporal y nocional) (1962: 127). Cada preposición no tiene a nivel de "lengua" más que una significación, y esta significación está formada por la reunión de un cierto número de rasgos pertinentes que forman una imagen susceptible de ser dibujada grosso modo. Esto se complementa añadiendo que es en el discurso donde las preposiciones adquieren matices nacidos del contexto. Esta opinión está basada en el principio de que un valor espacial ha dado origen a uno temporal, por extensión de significado y, a su vez, a uno nocional, tal como en: Llegó a Madrid (espacial) $\rightarrow$ Llegó a las cuatro de la tarde (temporal) $\rightarrow$ Llegó a una conclusión errónea (nocional). 
el término (o situación "lejos de"). López ilustra esta significación con el esquema tomado de Pottier, donde ' $\mathrm{B}$ ' es el término del movimiento $\mathrm{y}$ ' $\mathrm{v}$ ' representa el 'punto de mira' donde uno se sitúa:

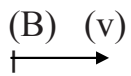

La autora aclara en nota que tendría que trazarse un esquema especial para el uso de la preposición 'de' en frases del tipo el hijo de Antonio, los pobres de la ciudad, etc., donde se establece una relación estática (con efecto de posesión). La representación correspondiente a esta 'de' sería: “indicando una relación puramente estática" (1972: 135). Sin embargo, no aparece tal esquema y aunque apareciera, este uso posesivo no se encuentra relacionado con los demás usos. Es decir que no hay una verdadera sistematización.

Desde un punto de vista más cercano a la pedagogía, Luque Durán (1980) escribe un manual dedicado a un público estudiantil, más específicamente, a estudiantes extranjeros de español. En su libro, este autor recopila 29 usos adnominales sin sistematizarlos, donde varios de ellos podrían subsumirse en lo que se conoce como posesión.

Morera (1988), por su parte, intenta una sistematización de las preposiciones españolas a través de un método estructuralista de pruebas de reconocimiento. El procedimiento de este autor para analizar las preposiciones consiste en proponer deductivamente una hipótesis semántica para cada una de ellas y luego verificarla en el discurso. Seguidamente, realiza un estudio concreto de los usos en el habla, teniendo en cuenta la significación del regente y los matices contextuales ${ }^{3}$. Cada preposición se describe mediante una combinación específica de rasgos atribuidos según un esquema binario (rasgos abstractos y difícilmente accesibles), donde 'de' se define como [+sentido; -concomitante; +eféresis; -extensión] ${ }^{4}$. Sin embargo, mediante su método opositivo de rasgos, 'de' no cubre los múltiples usos,

3 Por "matices", Morera entiende una amplia gama de significados, desde matices temporales, espaciales y nocionales, que abarcan los sentidos agentivo, final, causa, compañía, instrumento, etc., hasta, por ejemplo, un matiz de violencia en la preposición $a$ en la frase "arrojar cal $a$ la pared".

4 Donde: sentido: circunstancia de posición o desarrollo que parte de, pasa por o se dirige a un objeto designado por el régimen preposicional; concomitancia: indeterminación del sentido, zona intermedia del vector (no existe un punto de referencia externo que fije una dirección determinada); eféresis: la posición o el desarrollo del sentido es un alejamiento o un movimiento retrospectivo, que parte del punto de origen del vector; extensión: implica que la posición o el desarrollo del sentido se manifiesta con dimensiones (-extensión: la tendencia 
y para poder explicarlos, este autor recurre a una serie de matices ad hoc casi infinitos.

Granvik (2003), en el marco de la Gramática Cognitiva, propone una sistematización del ítem polisémico 'de'. Su trabajo tiene dos objetivos principales: por un lado, comparar los distintos usos de esta preposición documentados en el Libro del caballero Zifar y El ingenioso hidalgo don Quijote de la Mancha, con el propósito de estudiar la evolución de las preposiciones durante los siglos XIV, XV y XVI. Por otro, describir los distintos valores contextuales de 'de', estableciendo una red esquemática. En esta red, Granvik propone dos prototipos para 'de': 'separación' y 'posesión'. Sin embargo, el esquema resulta problemático en tanto no hay ninguna relación entre los dos prototipos propuestos. No hay relación entre la separación y la posesión, cuestión que es explicitada por el autor en el cuerpo del texto, y que se ve graficada con una línea divisoria en el esquema planteado (2003: 157). Cabe destacar, asimismo, que el estudio de Granvik resulta un aporte desde lo diacrónico y trabaja con corpus escrito, en contraste con la propuesta del presente trabajo, que analiza un corpus sincrónico y oral.

En un trabajo reciente, Granvik (2012) profundizó su estudio diacrónico. Analizó el uso de la preposición 'de' sobre la base de un corpus diacrónico, con énfasis en las diferentes relaciones semánticas que esta preposición establece. Entre las conclusiones a las que arriba se destaca la estabilidad del significado de la preposición 'de': "El uso de de sigue siendo esencialmente el mismo en la actualidad que hace 800 años" (2012: v). Además, según el autor, se percibe un aumento del uso de de como complemento nominal, al contrario de lo que ocurre con su uso como complemento verbal. En el contexto nominal son especialmente las relaciones posesivas más abstractas las que se hacen más frecuentes, mientras que en el contexto verbal las relaciones que se hacen menos frecuentes son las de separación/alejamiento, causa, agente y partitivo indefinido.

Las conclusiones de Granvik (2012) refuerzan la hipótesis postulada en el presente trabajo de que el significado de posesión es el valor prototípico de la preposición 'de'.

Por último, Rodrigues (2009) postula que la preposición 'de' no sugiere el "alejamiento de un límite", ni mucho menos la procedencia, sino que sería un referente conceptual: indica simplemente el concepto implícito en el elemento terminal de la relación (2009: 360). Como referente conceptual,

del alejamiento o de la aproximación no tiene dimensiones). Morera toma estos valores de Guillaume (Morera 1988: 87 y ss.). 
la preposición 'de' puede asumir cualquier nivel en el habla, yendo del plano estativo al dinámico y estableciendo relaciones de toda índole. No resulta transparente ni explicativo el término 'referente conceptual', al tiempo que no se logra una sistematización clara ni autoconsistente.

\subsection{LA NOCIÓN DE 'POSESIÓN'}

Entre las Gramáticas que dedican algún apartado a la noción de posesión, se destacan las siguientes: Lenz (1935: §28) define la posesión como el dominio que ejerce una persona sobre otra (mi hijo), sobre un animal ( $m i$ perro) o sobre un objeto ( $m i$ casa). Engloba las relaciones interpersonales, los inalienables, y la posesión abstracta. Relaciona esta última con el significado de cualidad. Roca Pons (1960: 190) y Alcina Franch y Blecua (1975: §3.4.2.2.) también plantean una concepción amplia de la posesión, ya que contemplan que el poseído sea [+/-humano] o incluso abstracto. Gili Gaya (1955: §190), por su parte, señala que la posesión es la relación entre propietario y cosa poseída, mientras que la pertenencia sería lo contenido, la relación parte/todo.

Desde una perspectiva generativista, Di Tullio (1997: 158) advierte que la diferente relación que el núcleo establece con el complemento y con un modificador de posesión se refleja en la mayor o menor precisión del sentido que podemos asignar a la construcción en su conjunto. Mientras que cuando se trata de un argumento, el significado es unívoco (el padre de Juan solo puede designar a su progenitor), cuando se trata de un modificador, por lo general, existen varias interpretaciones posibles. Así, la computadora de mi padre puede referirse a una pertenencia suya o a la que hay en su oficina o a la que desea adquirir. Como se observará, es una definición sobre todo sintáctica, donde se atiende a la naturaleza del constituyente (modificador o complemento), más que a su especificación semántica.

En el mismo sentido, la Gramática Descriptiva de Lengua Española (GDLE 1999: §15.2.3. y §15.2.4.) formula una larga lista de construcciones posesivas, atendiendo solo a la estructura argumental y a la prueba de reconocimiento de la pronominalización. Según esta prueba, una construcción es o no posesiva (solamente) si puede pronominalizarse: La entrada de Juan $\rightarrow$ Su entrada; La tía de Carlos $\rightarrow$ Su tía, y así. No hay mayores precisiones acerca del estatuto semántico de la noción de 'posesión'. 
La Nueva Gramática de la Lengua Española (NGLE 2009) describe una concepción bastante amplia del concepto de posesión ${ }^{5}$. Sin embargo, también recurre a la prueba de la pronominalización como única característica definitoria de las construcciones posesivas (2009: §18.2, §18.5).

Fuera de las Gramáticas, Vaamonde (2011), en un estudio sobre la alternancia posesiva con nombres de partes del cuerpo a partir de un corpus del español peninsular, afirma que la posesión es un dominio de carácter universal, esto es, que todas las lenguas han de contar con algún procedimiento convencionalizado para expresar una relación posesiva. En nota al pie, este autor advierte que el concepto mismo de posesión, como noción general, presenta dificultades para ser definido con carácter universal. Generalmente se lo relaciona con la idea de control del poseedor sobre lo poseído, de contigüidad espacial entre estos, de pertenencia, de esfera de influencia o, sencillamente, de relación abstracta entre dos entidades (2011: 63-64).

\subsection{La posesión según la Gramática Cognitiva}

Desde la Gramática Cognitiva, Langacker (1991: 167-180) advierte que la posesión no se reduce a la noción de 'propiedad de alguna cosa', sino que se necesita una caracterización más abstracta para albergar a todas las relaciones que codifica ${ }^{6}$. En este sentido, este autor establece el modelo cognitivo idealizado del punto de referencia (MPR), según el cual algunas entidades son más fáciles de localizar en referencia a otras entidades. El mundo es concebido como un lugar donde habitan objetos de diverso carácter.

\footnotetext{
5 Las construcciones posesivas expresan variadas relaciones, como inclusión, pertenencia o atribución, de parentesco, personales, sociales (mis amigos, tu jefe), de afiliación ( $t u$ partido), preferencia (su equipo de fútbol), y gran número de propiedades, características o atributos -sean físicos o no- de las cosas o las personas (mi peso, tu actitud, mi cumpleaños, tu presencia) (NGLE 2009: §18.5a, §18.5d).

6 Por ejemplo, lo poseído puede constituir: una parte (mi codo); un grupo (su equipo); un pariente (tu primo); otro tipo de relación interpersonal (su amigo); algo propio (su reloj); algo no propio (la cuna del bebé); algo manipulado (mi torre -de ajedrez); algo a disposición de uno (su oficina); algo cobijado (las pulgas del gato); una cualidad física (su salud); una cualidad mental (su paciencia); una locación transitoria (mi lugar); una locación permanente (su hogar); una situación (su aprieto); una acción llevada a cabo (su partida); una acción sufrida/experimentada (el asesinato de Lincoln); algo seleccionado (mi caballo, al que aposté); algo que cumple una función particular (tu ómnibus); alguien que sirve en un trabajo oficial (nuestro Mayor); y así indefinidamente (1991: §4.3.2.1.).
} 
Estos objetos varían en su saliencia ${ }^{7}$ según un observador dado: como las estrellas en un cielo nocturno, algunas son inmediatamente visibles para el observador, mientras que otras sirven como puntos de referencia para encontrar a las demás.

Este modelo constituye la base para definir una noción de posesión abstracta que represente todo lo que comparten las expresiones posesivas. En el MPR, el conceptualizador traza un camino mental desde el punto de referencia hasta el blanco (target). El punto de referencia es el poseedor, mientras que el blanco es la entidad poseída. Las relaciones de parte/ todo y las interpersonales están claramente construidas sobre este modelo donde una entidad funciona como punto de referencia para localizar a la otra. En cuanto a la posesión abstracta, la relación entre esta y la posesión prototípica es análoga a la de cualquier contraste entre concreto y abstracto. La noción abstracta es una cuestión de conceptualización. Finalmente, en las nominalizaciones (su partida; el asesinato de Lincoln), el nombre deverbal representa una reificación de un proceso y, por lo tanto, establece de por sí una relación abstracta. Por el contrario, el poseedor es un participante en el proceso cosificado, y generalmente es una persona o una entidad física, lo que lo convierte en un punto de referencia.

El MPR resulta crucial para entender la organización del ítem polisémico 'de' en forma de categoría radial. También resulta vital la cuestión de concebir la noción de posesión como una conceptualización (posesión abstracta), de la que se parte para llegar a relaciones más concretas y específicas.

Taylor (1995: 202-206), por su parte, analizó específicamente el concepto de posesión desde una perspectiva cognitiva y bajo la teoría de prototipos (Rosch 1973; 1977; 1978). Según Taylor, las características de la posesión prototípica son las siguientes (1995: 202):

1. El poseedor es un ser humano.

2. El poseído es una cosa concreta específica.

3. La relación es exclusiva: por cada cosa poseída hay solo un poseedor.

4. El poseedor tiene el derecho de hacer uso del poseído.

La saliencia se determina según los siguientes principios cognitivos: un todo es más saliente que sus partes; un objeto físico es más saliente que una entidad abstracta; y una persona tiene la máxima saliencia cognitiva. Por lo tanto, el todo tiende a ser el poseedor de sus partes (y no a la inversa), ya que su prominencia visible lo hace susceptible de ser punto de referencia. Del mismo modo, las personas son dueñas de las cosas y no a la inversa, porque están más individualizadas. 
5. Los derechos del poseedor sobre el poseído surgen de una transacción, como ser compra, donación o herencia. Los derechos permanecen con él hasta que en una posterior transacción (venta, regalo, legado) se los transfiere a otra persona.

6. El poseedor es responsable por el poseído. Se espera que lo cuide y que lo mantenga en buenas condiciones.

7. Para que el poseedor pueda ejercer sus derechos y deberes sobre el poseído, tanto poseedor como poseído tienen que estar en próxima cercanía espacial.

8. La relación de posesión es de largo plazo, medida en meses o años más que en minutos o segundos.

9. La relación de posesión suele tener una referencia específica: La casa de Juan identifica una casa específica.

Se parte de la caracterización de Taylor para describir los atributos de las construcciones nominales con 'de' bajo estudio. Se observa que los atributos están relacionados con la noción de posesión como propiedad, resultado de un intercambio mercantil. Este también parece ser el planteo de los gramáticos que remiten a la idea de 'dominio'.

Considerando los aspectos sobre la temática que falta estudiar, en el presente trabajo se construirá el ítem polisémico de la preposición 'de' en función adnominal, desde una perspectiva cognitiva, y sobra las bases del Modelo cognitivo idealizado de punto de referencia, propuesto por Langacker; el modelo de categorías radiales de Lakoff y los atributos de la posesión postulados por Taylor.

\section{EL ÍTEM POLISÉMICO 'DE'}

\subsection{El MODELO DE CATEGORIZACIÓN RADIAL DE LAKOFF}

Lakoff (1987) propone la teoría de categorización radial para estudiar la polisemia. En una categoría, los atributos pueden tener distinto peso. Por ejemplo, el concepto de 'pájaro' puede ser usado para designar un aeroplano (por proyección metafórica). En este sentido, se entiende que las extensiones 
metafóricas son menos salientes que las otras ${ }^{8}$. El modelo de categorías radiales puede resumirse en los siguientes puntos:

1. Los items polisémicos consisten en un número de categorías relacionadas en forma radial, con un sentido central.

2. Las extensiones semánticas se agrupan alrededor del miembro central y se relacionan por 'semejanza de familia' (concepto que Lakoff toma de Wittgenstein 1988[1953]) mediante una gran variedad de enlaces, tales como esquemas de imágenes ${ }^{9}$, y proyecciones metafóricas y metonímicas.

3. Los sentidos no centrales están motivados por el sentido central. Son predecibles, no arbitrarios.

4. El miembro central de la categoría provee un modelo cognitivo que motiva los significados no centrales.

El ejemplo de categoría radial frecuentemente citado es el de madre:

The concept mother is not clearly defined, once and for all, in terms of common necessary and sufficient conditions. There need be no necessary and sufficient conditions for motherhood shared by normal biological mothers, donor mothers (who donate an egg), surrogate mothers (who bear the child, but may not have donated the egg), adoptive mothers, unwed mothers who give their children up for adoption, and stepmothers. They are all mothers by virtue of their relation to the ideal case, where the models converge. That ideal case is one of the many kinds of cases that give rise to prototype effects (Lakoff 1987: 76).

El sentido central de la categoría madre sería el caso ideal, es decir, el de una mujer casada o en pareja que tiene un hijo biológico. Luego, algunos miembros son extensiones del sentido central ('madre adoptiva', 'madrastra'). Otros miembros se generan por la convención social y la cultura

8 Esto es así desde un punto de vista lógico (el significado metafórico es una extensión), desde el punto de vista psicológico (el significado metafórico se almacena por menos tiempo en el lexicón mental del hablante) y desde un punto de vista estadístico (el significado metafórico es menos frecuente que el literal). (Lewandowska-Tomaszczyk 2007: 147).

9 Los esquemas de imágenes se definen como representaciones de experiencias específicas. Estos esquemas estructuran nuestras experiencias físicas, pero también las que no tiene un carácter físico, a través de la metáfora. Ejemplos: de espacio (arriba-abajo; delante-detrás; izquierda-derecha; cerca-lejos; centro-periferia; contacto); de escala (trayectoria); de contenedor (continente; dentro-fuera; superficie; lleno-vacío; contenido); de fuerza (equilibrio; resistencia; compulsión; restricción; capacitación; bloqueo; desviación; atracción, etc.) (Lakoff 1987: 453). 
(por ejemplo, la mujer anciana que cobija al hijo de otra mujer dentro de una misma comunidad o la hermana de la madre en la cultura japonesa).

Debido a que este modelo resulta pertinente para estudiar la polisemia, se tomará para analizar el ítem polisémico 'de'. La preposición 'de' constituye una categoría radial, en tanto sus significados se relacionan a la manera de semejanza de familia.

\subsection{HIPÓTESIS Y DESCRIPCIÓN DEL ÍTEM POLISÉMICO 'DE’}

En el presente trabajo, se propone la hipótesis de que los valores semánticos de la preposición 'de' están organizados sistemáticamente y constituyen un ítem polisémico. El uso de 'de' con valor posesivo es el que muestra la mayor acumulación de atributos en común con el resto de los usos, por lo que se propone como el valor prototípico. Los demás significados se relacionan por pérdida de atributos o por semejanza de familia.

Se parte de los atributos de Taylor para describir las construcciones posesivas; se emplea el modelo de categorías radiales de Lakoff para representar la estructura semántica del ítem polisémico 'de'; y se toma el modelo cognitivo idealizado del punto de referencia de Langacker como sustento teórico de las ligazones entre los diferentes significados de 'de' en contexto adnominal. Los ejemplos analizados se extrajeron del corpus El habla culta de la Ciudad de Buenos Aires. Materiales para su estudio (HCCBA 1987), donde están registrados usos de la década de 1960.

A partir de los significados encontrados, es posible armar el ítem polisémico de la preposición 'de' en función adnominal como se observa en el Esquema I. 


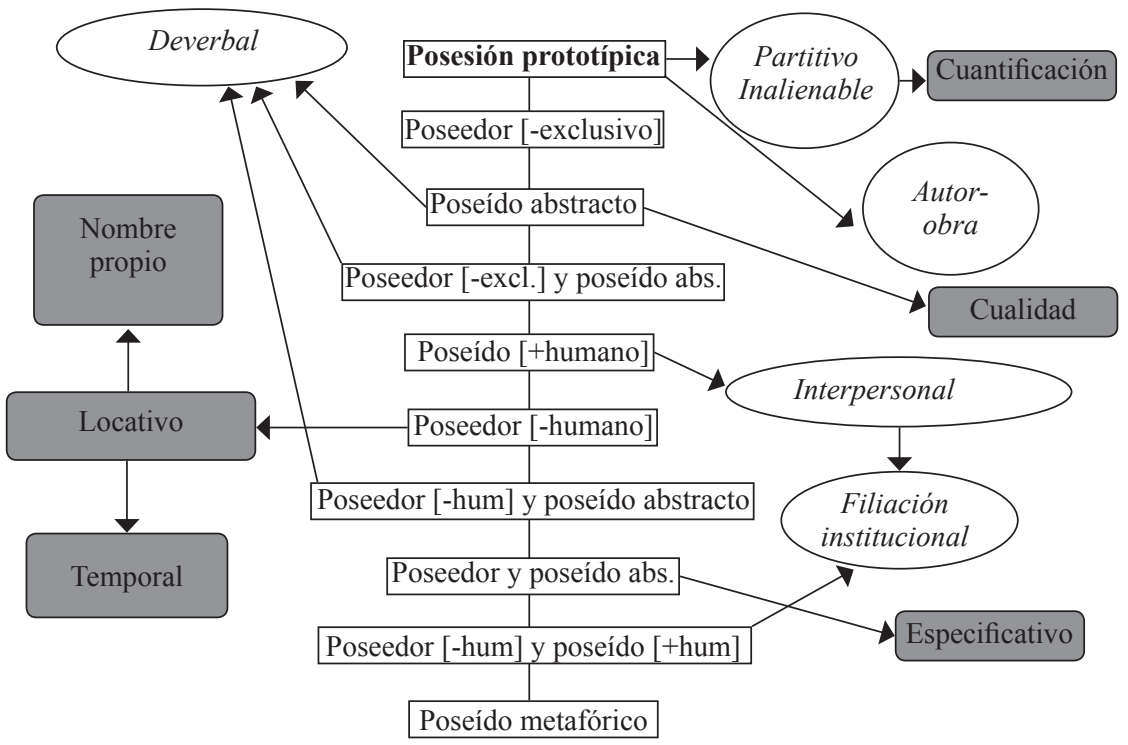

Esquema I. Ítem polisémico 'de'

En el Esquema I se diferencia una zona central que reúne los atributos semánticos que van a guiar las extensiones cercanas hacia abajo, y luego, las relaciones hacia otras categorías y subcategorías. En la zona central (cuadrados rectangulares), se parte de la posesión prototípica (La casa de tus padres, muestra III). Hacia abajo, se desprende una escala de construcciones posesivas donde se observa pérdida de uno o de varios atributos con respecto al prototipo: en primer lugar, se pierde el carácter exclusivo del poseedor ( $l a$ casa de los tíos abuelos, muestra XIII); luego, se pierde el carácter concreto del poseído, que pasa a ser abstracto (los valores de los jóvenes, muestra IX). Le sigue la combinación de estos dos factores (poseedor [-exclusivo] y poseído [-concreto]) (la actitud de la población, muestra XVII). Más alejadas aún, se encuentran las construcciones de poseído [+humano] (ayudante de un contador, muestra I). Por último, las construcciones más alejadas son las de poseedor [-humano] (el diario de la quinta, muestra XXIV) ${ }^{10}$, ya que el

10 Véase el ejemplo en contexto para apreciar mejor las características: "Inf. B. -No nos olvidemos que el diario--- es... es... es... es la materia de comercialización de vida más efímera. Inf. A. -Mhm. Inf. D. -Sí. Inf. B. -Porque tiene una vida de horas--- el diario de la 
atributo de poseedor [+humano] es el más importante de estas construcciones, como ya mencionaba Taylor. Siguen las combinaciones de poseedor [-humano] y poseído abstracto (los pilares del teatro literario latino, muestra $\mathrm{XX}$ ), ambas entidades abstractas (el drama de toda nuestra sociología, muestra II; la historia de la humanidad, muestra XVI), poseedor [-humano] y poseído [+humano] (donde se observa un intercambio de atributos) (la mucama del chalet, muestra XVI) y las proyecciones metafóricas como las menos salientes (El teatro de la hija del portero ${ }^{11}$, muestra XXVII).

De la zona central, se desprenden subcategorías (en cursiva). Estas subcategorías tienen en común algunos atributos con el prototipo o los derivados inmediatos, pero a su vez, agregan nuevos atributos. Se trata de las construcciones partitivas; la posesión inalienable; la relación entre el autor y su obra (las tres se relacionan directamente con la posesión prototípica); las relaciones interpersonales (donde se encuentra incluida la relación de parentesco), surgidas del poseído [-humano]; la filiación institucional (estrechamente relacionada con las construcciones de poseedor [-humano] y poseído [+humano]); y las construcciones deverbales (provenientes de las extensiones de poseído abstracto, poseedor [-exclusivo] y poseído abstracto, y poseedor [-humano] y poseído abstracto).

En los partitivos, se extrae una parte del poseedor (la parte del tambo, muestra XIII). En la posesión inalienable, lo poseído forma parte del poseedor (está incluido, es indivisible), como en el cabello de Osvaldito (muestra $\mathrm{XXV}$ ); el nuevo atributo sería que poseedor y poseído guardan una relación de inclusión, a la manera de contenedor/contenido (no son dos entidades diferenciadas, independientes). En la relación autor-obra, lo poseído es una creación del poseedor, es decir que no es un objeto preexistente, pero a su vez, el autor de la obra puede no poseerla estrictamente, en el sentido de ser el propietario (estas tragedias de Livio Andrónico, muestra XX). En cuanto a las relaciones interpersonales, se vinculan con la extensión de poseído [+humano]: se trata de un poseído [+humano] específicamente en relación interpersonal con el poseedor, puede ser amigo, compañero, socio, etc. (un amigo del marido, muestra XXVII). La relación de parentesco sería

quinta [edición] ya a la... a las diez de la noche ya no tiene vi... ya no tiene valor" ( $H C C B A$, muestra XXIV).

11 Aquí "teatro" está usado en sentido metafórico. El ejemplo en su contexto es: "pero ahora que no tenemos más el teatro de la hija del portero, por lo menos nos entretenemos con ese ruido. El portero que antes estaba acá se jubiló, se fue, y los domingos era divertidísimo porque venía... se casó la hija... la hija, pero cuando estaba de novia venía a comer el novio y se peleaban muchísimo siempre" (HCCBA, muestra XXVII) En este contexto, "teatro" alude a las continuas peleas de la hija del portero con su novio. 
una especificación de la interpersonal, indica relaciones familiares (padre, madre, esposo/a, hermano/a, etc.) (El padre de Susana, muestra XIII). La relación de filiación institucional es más abstracta, ya que hay una entidad detrás, es decir que el poseedor pierde carácter humano, mientras que el poseído es humano (Presidentes de las Academias, muestra XII). Finalmente, los nominales deverbales también surgen de los poseídos abstractos: la relación de posesión toma dinamismo y se acerca al modelo cognitivo idealizado de bola de billar ${ }^{12}$ (o extensiones como los verbos de acción con un solo actante). En el corpus se encuentran dos variantes: construcciones con agente (la actividad de Larrague, muestra XIII) y construcciones con paciente (el descubrimiento de una nueva hormona por el doctor Deworner en Inglaterra, muestra VI; donde "una nueva hormona" es el paciente de "descubrimiento", y ya no puede hablarse de posesión, sino de MCI de bola de billar con traspaso de energía de un agente a un paciente).

En los márgenes del ítem polisémico, se encuentran otras categorías (en color gris), relacionadas con algunas subcategorías o con alguna extensión inmediata del prototipo: la categoría 'cuantificador', que se relaciona con las construcciones partitivas (de hecho, para algunos teóricos, como Morera, el sentido partitivo es este sentido que aquí denominamos 'cuantificador'), pero donde la construcción sería más bien una gramaticalización, ya que la preposición forma una unidad semántica con el basamento (el determinante) y el sustantivo o pronombre en cuestión (una de las cosas, muestra I). También se encuentra la categoría 'especificativo' (denominada 'asunto' por otros teóricos), que surge de la posesión abstracta. Por ejemplo, en problema de gastroenterología (muestra I), la preposición 'de' enlaza dos entidades abstractas, de modo de especificar el tipo de problema. Otras categorías relacionadas son las de 'locativo', 'nombre propio' y 'temporal'. En la relación locativa, lo que sucede es que el poseedor es poco prototípico en tanto es [+/-concreto], y específicamente se trata de un poseedor locativo (la Galería Plástica de la calle Florida, muestra IX). Se denomina 'nombre propio' al locativo gramaticalizado, como en Universidad de Cambridge (muestra XII). La relación temporal, en tanto, sería una proyección metafórica del locativo (ocho de la mañana, muestra I).

En última instancia, se encuentra la categoría 'cualidad', surgida de la posesión abstracta. Algunos gramáticos ya señalaban este tipo de relación

12 El MCI bola de billar (o cadena de acción), da cuenta de la conceptualización prototípica (o no marcada) de un evento a través de una cláusula activa transitiva. Según Langacker, el hablante (o conceptualizador) percibe un traspaso de energía de un agente hacia un paciente (Langacker 1991: 13 y ss.). 
intercategorial, como Lenz, aunque por supuesto sin analizar la preposición 'de' bajo los lineamientos de la teoría de categorización radial. Este gramático daba ejemplos como La hermosura del niño, donde el poseído es abstracto pero a la vez es una cualidad, un atributo (El niño posee hermosura, El niño es hermoso). En el corpus bajo estudio, además, se encontraron solo tres casos de significado de cualidad: una profesora de muy alto vuelo (muestra I); el área de mejor nivel (muestra XVII); nivel de ingresos más bien altos o de medios para arriba (muestra I).

\section{ANÁLISIS DE EJEMPLOS}

A continuación, se analizarán ejemplos de subcategorías y categorías, para observar de qué manera se relacionan con los sentidos centrales. Se destaca en negrita el nominal analizado.

\subsection{SUBCATEGORÍAS}

\subsubsection{Ejemplo de relación partitiva}

(1) Enc. -Ahora--- en cuanto a la relación con los peones--- ¿cómo se contratan los peones? Eso me interesaría que me contara--- si son estables--o...

Inf. -Bueno--- hay de todo. General... el... generalmente... Bueno--- el encargado que también tiene... está un poco habilitado, sí.

Enc. - ¿Un poco habilitado? ¿En qué sentido?

Inf. -Tiene una pequeña habilitación--- en los product... [interrupción] Después... esté... nosotros tenemos--- un peón--- que se llama peón de campo. Se considera peón de campo... es el... el que trabaja en el campo, que tiene que recorrer--- que tiene que--- auxiliar--diríamos--- al encargado en todo lo que sea el campo. Además nosotros tenemos un puestero... eh... quiere decir que no está en el casco propiamente dicho, sino que está en una población--- que está dentro de los límites del campo--- entonces... eh... el puestero ya se toma siempre una persona con familia... eh... con hijos--generalmente--- Nosotros en este momento tenemos un hombre con mujer y dos hijos (HCCBA, muestra XVI). 
El ejemplo (1) es un fragmento de una entrevista a una mujer que habla sobre la historia del campo donde vivía. En la descripción espacial del campo, se hace referencia al "casco", que sería la parte central, y luego a "los límites del campo". En este nominal, la preposición 'de' establece una relación partitiva, ya que se extrae una parte del todo, se extraen los límites del todo formado por el campo. El significado partitivo se relaciona directamente con la posesión prototípica. El nuevo atributo es que poseedor y poseído guardan una relación de inclusión, entendida en términos del esquema de imagen parte/todo (Lakoff 1987: 272). Los elementos del esquema son el todo, las partes y una configuración que los relaciona. La lógica consiste en que existe una asimetría entre el todo y las partes: si A es una parte de $\mathrm{B}$, entonces B no es una parte de A. Es decir, pueden existir las partes sin el todo, pero no a la inversa. Además, para que exista el todo, las partes deben tener una configuración. Se entiende, entonces, que el campo y sus límites (físicos) no son dos entidades independientes.

\subsubsection{Ejemplo de relación de posesión inalienable}

(2) Inf. -la que me encanta es Carson Mc Cullers, ¿leíste La balada del café triste?

Enc. -Ah, sí- - - sí.

Inf. - ¿Te gustó?

Enc. $-[\ldots \ldots . . .$.

Inf. -Carson Mc Cullers. Además la cara de Carson Mc Cullers es una maravilla (HCCBA, muestra XXX).

Al igual que en el caso de la relación partitiva, la relación de posesión inalienable también deriva de la posesión prototípica y también se entiende a partir del esquema de parte/todo. Sin embargo, a diferencia de la partitiva, no se extrae una parte del poseedor sino que se hace foco en uno de los elementos integrantes del todo. Ese elemento puede conceptualizarse por separado (tenemos una representación mental de lo que es una cara). En el ejemplo (2), se observa que "la cara" mantiene una relación de posesión inalienable con Carson Mc Cullers, la escritora norteamericana.

\subsubsection{Ejemplo de Relación autor-obra}

(3) Inf. B: -Eso de que los alemanes hablen cate... eh... catorce idiomas--- es un cuento chino. Los alemanes que hablan varios idiomas son los suizos, porque sí; entonces sí, pero por razones--- étnicas y qué sé yo. Pero los alemanes no hablan veinte idiomas, hablan alemán. 
Inf. A. -Si hasta cantan las óperas de Verdi en alemán.

Inf. B. -Sí sí. Bueno, eso es... En Italia cantan las óperas de Wagner en italiano.

Inf. D. -Sí, cantan--- por supuesto...

Inf. A. -En italiano. Son fantásticos, son fantásticos (HCCBA, muestra XXIV).

La relación que establece 'de' entre el autor y su obra (entre Verdi y Wagner, y las óperas, respectivamente) deriva de la relación de posesión prototípica. El nuevo atributo es que los autores son poseedores de sus obras en el sentido de que las han creado, pero no son necesariamente sus propietarios. Lo poseído, en tanto, no es preexistente sino que depende del autor, ya que es una creación. Se entiende en términos del esquema del enlace (Lakoff 1987: 274): hay dos entidades interconectadas y existe una asimetría: siendo el autor, A, y la obra, B; A crea B, por lo tanto, B no puede existir sin A. Hay un enlace permanente entre los dos elementos.

\subsubsection{Ejemplo de relación interpersonal}

(4) Inf:: -por ejemplo, yo el año pasado di clases sobre un Rorschach--- y que era de una joven de diecinueve años, estudiante universitaria, que tenía- - bueno--- que me la enviaban para que yo le hiciera sicoterapia. Y yo, a través del Rorschach--- y de la manera en que se expresaba en las respuestas--- pude detectar algo de base orgánica. Era hija de un distinguido

cirujano. Se había casado a los diecisiete años y había tenido un chico (HCCBA, muestra XIV).

Las relaciones interpersonales derivan de la relación de posesión en la que lo poseído es [+humano]. También puede entenderse en términos del esquema del enlace: el hombre establece lazos sociales con otras personas. Esos lazos pueden permanecer o romperse. En (4), "hija de un distinguido cirujano" hace referencia al lazo de parentesco entre el "poseedor", un distinguido cirujano, y su hija, "lo poseído". Los ejemplos de este tipo también dan cuenta de la interpretación del concepto de posesión en términos de dominio: puede concebirse a un [+humano] como objeto poseído desde el punto de vista de las relaciones sociales, donde puede haber dominio de uno sobre otro (padre/hijo; jefe/empleado) o relaciones de igualdad de poder, como en el caso de la amistad. 


\subsubsection{Ejemplo de filiación institucional}

(5) Inf. -Estuve en Estados Unidos dos veces. Estuve en el cincuenta, del cincuenta al cincuenta y dos. Estuve en Boston, estuve con mi esposo. Pasé dos años magníficos. Él era estudiante de Harvard y yo fui la esposa del estudiante de Harvard con un bebé de dos años, y lo pasé realmente muy bien. Y--- es más--- me dieron un... un diploma, el diploma... eh... mi familia acostumbra a decir que yo colecciono diplomas, pero el diploma más pintoresco que tengo, es el diploma que me dieron en Harvard: "A la sufriente esposa de un estudiante de Harvard y summa cum laude" [risas]. Ninguno de los otros diplomas que tengo es summa cum laude (HCCBA, muestra X).

En (5), la entrevistada se refiere al marido con el nominal sin basamento ( sin determinante) "estudiante de Harvard". En este caso, la preposición 'de' establece una relación de filiación institucional, derivada de la relación de posesión donde el poseedor es [-humano] y el poseído [+humano]. Es decir, se observa una inversión en la caracterización de poseedor y poseído: los dos son muy poco prototípicos. Además, el poseedor [-humano] corresponde a una entidad locativa. Esta relación puede entenderse en términos del esquema del punto de partida y, por proyección metafórica, del esquema de parte/ todo: "Harvard" funciona como el lugar de origen del estudiante, un lugar que posee estudiantes (y profesores) para constituirse como Universidad. El estudiante no puede conceptualizarse de ese modo si no se lo concibe en relación con ese locativo de origen donde pertenece, del que es parte.

\subsubsection{Ejemplo de relación deverbal}

(6) Enc. - ¿Y toda la posición de Melanie Klein sobre la influencia de--- lo prenatal y de las... los primeros meses?

Inc. -Bueno--- no--- yo de lo prena... bueno, lo prenatal yo no sé si es de Melanie Klein o si son--- innovaciones de Arnaldo Rascovsky, más bien, que quería matarle un poco el punto a Melanie Klein, y como Melanie Klein...

Enc. -Por lo menos en los primeros meses... (HCCBA, muestra XIV).

En el ejemplo (6), el entrevistador se refiere a los avances del psicoanálisis en la época (década del 60). Menciona especialmente las "innovaciones de Arnaldo Rascovsky". En este nominal, la preposición 'de' conecta un sustantivo abstracto deverbal (con estructura de actantes) con un nombre propio. Esta relación deriva de la posesión abstracta (y combinaciones como poseedor [-exclusivo] y poseído abstracto; y poseedor [-humano] y 
poseído abstracto). En este caso, el poseedor es [+humano], y lo poseído es un nombre deverbal, lo que significa que hay un proceso reificado: la acción de innovar por parte de Rascovsky es vista como una acción realizada, y por tanto, cosificada (además, recibe plural, por lo que se conceptualiza como un objeto) en forma de sustantivo. La reificación facilita el hecho de que se lo conceptualice como un objeto poseído. Lo que Rascovsky "posee" son sus innovaciones. Esta relación se comprende mediante el esquema del enlace: hay un vínculo entre el poseedor y la acción cosificada como un objeto poseído (realizado), similar al vínculo entre el autor y su obra.

\subsection{CATEGORÍAS DIFERENCIADAS}

\subsubsection{Ejemplo de relación de cuantificación}

(7) Enc. -No, pero la música te gusta.

Inf. -Sí, la música es la única manifestación arti ... así artística que... que llega a gustarme y que puedo estar veinte horas escuchándola, siempre y cuando me guste y que no me aburra. Es decir, así las artes plásticas, por ejemplo, no me interesan y ni me preocupan, ¿no? Es decir, no me interesa la pintura ni la escultura; no ... no me atraen. A veces esté... me da mucha vergüenza, ¿no?, porque habla así un grupo de gente, pero como no... eh es auténtico en mí, no ... no me interesa, es decir, no... no, me llega, claro (HCCBA, muestra I).

En el ejemplo (7), en el nominal "un grupo de gente", la preposición 'de' establece una relación de cuantificación, ya que se conceptualiza "un grupo de" como una sola unidad gramaticalizada que tiene como objetivo cuantificar el sustantivo "gente". El designado se corresponde con una totalidad de personas. El cuantificador "un grupo de" señala que se trata de un grupo determinado (no de una parte de ese grupo). Esta relación está vinculada a la posesión a través de la relación partitiva, ya que el uso de 'de' como cuantificador extrae, cuantifica, precisa, un nombre.

\subsubsection{Ejemplo de relación locativa}

(8) Inf. -Cuando yo estaba en... los... en quinto grado y todo el secundario lo hice en casa de mi abuelo y en casa de mi tía. Primero en la calle Independencia; después, cuando murió mi abuelo se vendió la casa de la calle Independencia, en la calle Solís, donde todavía vivía... esté.. . mi tía hasta hace pocos años, y después, cuando terminé el secundario y entré a 
la facultad, entonces papá me sacó de la casa de mi tía y me mandó a vivir solo, y fue cuando yo fui a vivir a Villa Devoto (HCCBA, muestra XIII).

La relación locativa deriva de la posesión de poseedor [-humano]. En el ejemplo (8), en el nominal "la casa de la calle Independencia", la preposición 'de' establece una relación de posesión, donde el poseedor es un lugar geográfico, y lo que posee es un objeto prototípico, una casa. Se concibe como posesión mediante el esquema del contenedor (Lakoff 1987: 272). En dicho esquema hay un elemento que funciona como recipiente, con una parte interior, otra exterior y las fronteras. El otro elemento es lo contenido, que, por tanto, se encuentra dentro del recipiente. En el ejemplo, "la casa" es el contenido (lo poseído) que se encuentra incluido en el lugar "calle Independencia", que actúa como un recipiente contenedor.

\subsubsection{Ejemplo de relación temporal}

(9) Enc. -¿Así que pensás seguir... esté... pensás seguir estudiando? Te entró el bichito de...

Inf. $-¿$ Del estudio?

Enc. -Del estudio.

Inf. --Bueno, no tanto. En realidad lo que... esté... es una idea, ¿no? Ahora, cuándo me voy a poner a hacerlo creo... Claro--- cada vez uno se ve un poco más cercado por la falta de tiempo, ¿no? Eh... sobre todo... eh... estos últimos tiempos yo trabajaba de ocho de la mañana a doce del mediodía en esta empresa donde era contador (HCCBA, muestra I).

Por proyección metafórica, se deriva la relación temporal a partir de la relación locativa. En (9), se conceptualiza la mañana como un contenedor de períodos temporales donde se encuentra la hora 8 (lo mismo sucede con el mediodía y la hora doce). Se entiende el tiempo en términos del espacio.

\subsubsection{Ejemplo de relación de nombre propio}

(10) Enc. -Eso es lo que pasa. Cuando no pueden tragar la del estado se van a la privada, ¿no?, algunos van directamente a la privada.

Inf. -Sí, algunos van directamente a la privada. Ahora, por ejemplo, estoy... esté... estuve charlando también con una chica que es fonoaudióloga, recibida así en la Universidad de Buenos Aires, y está haciendo el doctorado en una universidad privada también (HCCBA, muestra I). 
En (10), la relación que establece la preposición 'de' en el nominal "Universidad de Buenos Aires" es la que aquí se denomina "nombre propio", ya que se trata de la gramaticalización de la relación locativa. "Buenos Aires" se concibe en primer lugar como poseedor locativo de la entidad [-humana] "Universidad", al punto que se gramaticaliza como nombre propio. Se conoce a la Universidad con ese nombre, como una especificación del lugar, más que como una relación de posesión con poseedor locativo. Se gramaticaliza porque se concibe como un todo la construcción nombre + de + nombre.

\subsubsection{Ejemplo de relación especificativa}

(11) Enc. -¿Cuánto hace que se inició esa carrera? [Se refiere a la carrea de Computación Científica].

Inf. -Y, esa carrera hace muy poquito, hace unos cinco años que se inició. Seis. Lo que sucede que se... como era una $m . .$. un apéndice, digamos, del departamento de matemáticas, así alguna gente de matemáticas seguía esa carrera y se recibieron [sic] así aisladamente muy poca gente que inclusive no sigue en contacto con la facultad, ¿no? (HCCBA, muestra V).

En (11), la preposición 'de', en el nominal “departamento de matemáticas", establece una relación especificativa, ya que precisa, caracteriza, el departamento. Precisa la carrera de la cual se encarga. Esta relación deriva de un tipo de posesión, muy poco prototípica, donde el poseedor es [-humano] y el poseído es abstracto. Este tipo de relación se encuentra en los márgenes del ítem polisémico, ya que no se conserva la idea estricta de posesión, sino que se establece sencillamente una relación entre dos nombres, de modo que el primero es identificado por medio del segundo. Queda el resabio de la posesión en la idea de que la carrera de matemáticas tiene un departamento propio, que versa sobre ella.

\subsubsection{Ejemplo de relación de cualidad}

(12) Enc. -Bueno, no tanto, ¿eh?, no tanto. Yo tengo referencias de una profesora que fue a enseñar creo que a la Universidad $Z$, fue a enseñar latín me parece, o no recuerdo qué, y me dijo que realmente era impresionante lo bajo del nivel del alumnado.

Inf. -Nivel del alumnado.

Enc. -Además le hicieron indicaciones. Y eso que ella no es así una profesora de muy alto vuelo, ¿no?

Inf. -Claro, claro, claro. 
Enc. -Le hicieron indicaciones de que bajara un poco el nivel porque no la podían seguir. (HCCBA, muestra I).

En (12), finalmente, la preposición 'de' establece una relación de cualidad, ya que atribuye al nombre "profesora" la característica de (no) ser de "muy alto vuelo". Esta relación surge de la posesión abstracta. Poseedor y poseído se encuentran invertidos: la preposición acompaña al atributo que posee el sustantivo precedente. La idea de posesión se mantiene en tanto la profesora es poseedora de sus cualidades. Lo poseído es inherente al poseedor ${ }^{13}$.

\section{CONCLUSIONES}

A partir del análisis de los ejemplos del corpus oral del español de Buenos Aires, se concluye que los usos adnominales de la preposición 'de' constituyen un ítem polisémico organizado mediante una estructura de categoría radial, sobre la base del modelo de punto de referencia. El uso prototípico de la preposición 'de' es el posesivo, sentido central de la categoría radial. Los atributos de la posesión prototípica observados en español coinciden con los que propone Taylor (1995).

Las extensiones cercanas al sentido central se dan por pérdida de atributos y se organizan de acuerdo con la siguiente escala, donde la jerarquía responde al peso de los atributos:

Posesión prototípica $>$ Poseedor [-exclusivo] $>$ Poseído abstracto $>$ Poseedor no exclusivo y poseído abstracto $>$ Poseído [+humano] $>$ Poseedor [-humano] $>$ Poseedor [-humano] y poseído abstracto $>$ Poseedor y poseído abstractos $>$ Poseedor [-humano] y poseído [+humano] > Poseído es metafórico.

13 La relación de cualidad, además, mantiene un vínculo con la noción de posesión desde el punto de vista histórico, como señala Granvik (2012: 152): "La séptima categoría [complementos de cualidad y de clase] puede considerarse parte de la relación posesiva por motivos históricos, en el sentido de que se relaciona con los usos del genitivo latino (el llamado genitivus cualitatis). Bassols de Climent (1967, I: 90), en su descripción del genitivo latino considera este uso 'una prolongación del posesivo', añadiendo que 'originariamente más que una cualidad expresaba pertenencia a una clase o categoría'". 
Las subcategorías, a su vez, se relacionan con el prototipo o con alguna de las extensiones centrales por compartir algunos atributos, pero se diferencian por agregar nuevos atributos (la relación partitiva, relación de posesión inalienable; la relación entre el autor y su obra; las relaciones interpersonales; la relación de filiación institucional; y la relación de nombres deverbales).

Finalmente, las categorías diferenciadas de la posesión pero de alguna manera relacionadas con ella son: cuantificador, locativo, temporal, nombre propio, especificativo y cualidad. A pesar de ser categorías distintas, se relacionan con alguno de los miembros del ítem polisémico mediante algún atributo.

El análisis cualitativo de los ejemplos seleccionados ha mostrado de qué manera se efectúan las ligazones entre los sentidos centrales de la preposición 'de' y las subcategorías y categorías diferenciadas.

\section{REFERENCIAS BIBLIOGRÁFICAS}

Alarcos Llorach, Emilio. 1994. Gramática de la lengua española. Madrid: Espasa Calpe. Alcina Franch, José y José Manuel Blecua. 1975. Gramática española. Barcelona: Ariel. Bassols de Climent, Mariano. 1967. Sintaxis histórica de la lengua latina. Vol. I. Madrid: Consejo Superior de Investigaciones Científicas, Patronato "Menéndez y Pelayo".

Bosque, Ignacio y Violeta Demonte (dirs.) 1999. Gramática Descriptiva de la Lengua Española. Madrid: Espasa-Calpe.

Di Tullio, Ángela. 1997. Manual de Gramática del español. Buenos Aires: Edicial. 1987. El Habla culta de la ciudad de Buenos Aires. Materiales para su estudio.

Tomos I y II, Buenos Aires: Universidad de Buenos Aires.

Fernández Lagunilla, Marina y Alberto Anula Rebollo. 1995. Sintaxis y Cognición. Introducción al Conocimiento, el Procesamiento y los Déficits sintácticos. Madrid: Síntesis.

Geeraerts, Dirk y Hubert Cuyckens (eds.). 2007. The Oxford Handbook of Cognitive Linguistics. Oxford: Oxford University Press.

Gili Gaya, Samuel. 1955. Curso Superior de Sintaxis Española. Barcelona: Spes.

GranviK, Anton. 2003. Estudio diacrónico comparativo de los usos y la semántica de la preposición DE en dos novelas españolas: Libro del caballero Zifar $y$ El ingenioso hidalgo don Quijote de la Mancha. Tesina de Pro gradu. Departamento de Filología Hispánica, Universidad de Helsinki Diciembre de 2003.

2012. De de. Estudio histórico-comparativo de los usos y la semántica de la preposición de en español. Helsinki: Société Néophilologique. Tesis doctoral.

Hopper, Paul. 1988. Emergent Grammar and the A Priori Grammar Postulate. En Deborah Tannen (ed.) Linguistics in Context: Connective Observation and Understanding, pp. 117-134. Ablex: Norwood $N^{\circ} 5$.

LaKoff, George. 1987. Women, fire and dangerous things. Chicago: Chicago University Press. 
Langacker, Ronald. 1987. Foundations of Cognitive Grammar. Theoretical Prerequisites, vol. 1. Stanford: Stanford University Press.

1991. Foundations of Cognitive Grammar. Descriptive Applications, vol 2. Stanford: Stanford University Press.

Lenz, Rodolfo. 1935. La oración y sus partes. Madrid: Nueva Revista de Filología Española.

Lewandowska-Tomaszczyk, Barbara. 2007. Polysemy, Prototypes, and Radial Categories. En Dirk Geeraerts y Hubert Cuyckens (eds.). The Oxford Handbook of Cognitive Linguistics, pp. 139-169. Oxford: Oxford University Press.

López, María Luisa. 1972. Problemas y métodos en el análisis de preposiciones. Madrid: Gredos.

Luque Durán, Juan de Dios. 1980. Las preposiciones, I y II, Madrid: Sociedad general española de librería S.A.

Morera Pérez, Marcial. 1988. Estructura semántica del sistema preposicional del español moderno y sus campos de usos. Puerto del Rosario, Servicio de publicaciones del Excmo. Cabildo Insular de Fuerteventura.

Pottier, Bernard. 1962. Systématique des éléments de relation. Paris: Klincksieck.

Real Academia Española. 1931. Gramática de la lengua española. Madrid: Espasa Calpe. 2009. Nueva Gramática de la Lengua española. Madrid: Espasa.

Roca Pons, José. 1960. Introducción a la gramática. Barcelona: Teide.

Rodrigues, José María. 2009. La lingüística de corpus y el análisis gramatical del español: propuesta de tratamiento de las preposiciones del español como especificadores semánticos. Valladolid: Universidad de Valladolid. Tesis doctoral.

Rosch, Eleanor. 1973. On the internal structure of perceptual and semantic categories. En Timothy E. Moore (ed). Cognitive development and the acquisition of language, pp. 114-144. New York: Academic Press.

1977. Human Categorization. En Neil Warren (ed.). Studies in Cross-Cultural Phsychology. London: Academic.

1978. Principles of Categorization. En: Eleanor Rosch y Barbara Lloyd. Cognition and Categorization, pp. 27-48. Hillsdale, N. J.: Lawrence Erlbaum Associates.

TAYlor, John. 1995. Linguistic Categorization: Prototypes in Linguistic Theory. Oxford: Clarendon Press.

Trujlllo, RAmón. 1971. Notas para un estudio de las preposiciones españolas. Thesaurus XXVI: 234-279.

VAamonde, Gael. 2011. La alternancia posesiva con nombres de partes del cuerpo. Un estudio descriptivo del español a partir de datos de corpus. Vigo: Universidad de Vigo. Tesis doctoral.

Wittgenstein, Ludwig. 1988[1953]. Investigaciones filosóficas. Barcelona: Crítica. 